\title{
Publications
}

Human Biogeography by Alexander $\mathrm{H}$. Harcourt (2012), vii + 319 pp., University of California Press, Berkeley, USA. ISBN 9780520272118 (hbk), USD 60.00/GBP 41.95.

A virus, $M r$ Anderson. Human beings are a disease, a cancer of this planet.' [Agent Smith to Neo, The Matrix, 1999, The Wachowski Brothers]

What can human evolutionary biogeography tell us about conservation or sustainability and therefore why should readers of Oryx be interested in this book? For two reasons: understanding the past is never analogous with predicting the future but this book provides elegant, accessible evidence for why, when and how humans spread over the face of the planet, and secondly it illustrates the risks that invasive species (e.g. humanity) pose to the survival of indigenous species as well as to themselves.

Alexander Harcourt has written a history of humanity's peopling of the globe, integrating the ethnographic with the ecological. The theoretical basis of the book is that physical, physiological and cultural adaptations among humans result from selection in the context of local environments. Harcourt is careful not to equate physical diversity among humans with selection for genetic variation; he discusses traits of culture (using language, which will no doubt strike cultural evolutionists as simplistic) as a means of illustrating spatially or geographically shared traits rather than causal modes of selection. As a synthesis of human evolution alongside historical and modern distributions and current adaptations, this book brings together the evolutionary/ biological nature of humans with their behavioural practices-where and how we live.

The book is phylogenetically comprehensive, moving in Part I from the biogeography of primates to 'out of Africa' dispersals of early Homo and then subsequent journeys of Homo sapiens to various new worlds. Recent genetic and archaeological evidence for the peopling of the Pacific is summed up as 'the situation is... complex'-as is true of many of Harcourt's arguments-but he makes an excellent effort to untangle complexities such as why genes linked to men and women seem to have moved differently and distinctly. Chapter 3 (Climate and hominin evolution and dispersal) can be read as an example of how to critically and statistically integrate fossil and archaeological evidence with changing climates over evolutionary time.

In Part II, interactions between humans and their environments that result in adaptations-to temperature, climate, elevation, nutrition and pathogens-and that influence our population sizes and structures, are set out. When and why these effects (e.g. Bergman's and Allen's rules, which predict size and shape adaptations to cold and latitude) operate in human populations are covered in detail. Chapter 6 (Use of area) has an excellent discussion of island miniaturization and includes the vexed Homo floresiensis of Indonesia as an example of our lack of understanding of the nature of human adaptability or of the processes of island biogeography. This chapter exemplifies the challenges posed by Harcourt: how do we start to rethink our explanations for human (linguistic, cultural) diversity on the basis of the biology of non-humans? Biogeography of variation in human diets is covered in Chapter 7, using examples of genetic markers for highly derived and specialized enzymatic capacities for digestion, along with some of the problems that ensue for the metabolism of prescription drugs. This chapter could have been expanded as there are potential implications for meeting human nutritional needs in the future. Part II is a comprehensive, interesting and well-structured approach to human biology as well as human distributions and numbers.

The final part covers the way human cultures compete, expand and go extinct, and the logic of these arguments is extended to the species that threaten humans (pests, parasites, pathogens), and the ways humans threaten others. This is a concise section, which could easily have been expanded into another book, but the focus remains on key elements of evolutionary significance, both for humans and the other species we have wiped out or transplanted along our way. Throughout this book a lay reader will find much of general evolutionary and ecological interest, while a specialist will also appreciate the excellent diagrams which re-figure in an accessible fashion data that are scattered throughout a voluminous literature (as evidence, the reference list is 56 pages and 861 separate articles and books!). Harcourt should be congratulated on writing a lucid book of such compelling general interest that should spark further interdisciplinary efforts to understand the human organism in its natural and socially constructed environment.

Phyllis C. Lee School of Natural Sciences, University of Stirling, UK

E-mail phyllis.lee@stir.ac.uk
Adaptive Collaborative Approaches in Natural Resource Governance: Rethinking Participation, Learning and Innovation edited by Hemant R. Ojha, Andy Hall and Rasheed Sulaiman V (2012), xviii + 327 pp., Earthscan, Oxford, UK. ISBN

9780415699105 (pbk) GBP 34.99/USD 59.95.

I have a confession to make: I'm easily seduced by book titles. So, while all the buzzwords in the title of this book may not get your heart racing, they were enough to prompt me to volunteer to read and review it. The editors define adaptive collaborative approaches as 'a family of concepts that seek to combine research and various other ways of learning as well as seek out collaborative actions among diverse stakeholders operating at multiple scales of decision-making and action'. Further, they state that they see adaptive collaborative approaches as 'a suite of strategies, rather than an absolute approach, which are employed to learn and muddle through complex systems to generate and facilitate innovations on various aspects of resource governance and management'.

And therein lies the rub. The editors' multiple contributions to this publication suffer from an excess of jargon wrapped up in long and complex sentences. Perhaps this is inevitable given the subject matter. Indeed, in her chapter entitled The ups and downs of institutional learning, Carol Colfer reflects that the complexity of the language used by her social science team mystified their natural science colleagues. She reports this as one of the major challenges to the adoption of adaptive collaborative approaches within the Center for International Forestry Research. Less forgiveable are the typographical and editorial errors in the introductory chapter (and elsewhere) that in themselves may be enough to put the reader off delving deeper into the subsequent contributions. That would be a real shame given that there is much material of real interest here.

Chapter 2 provides a review of the conceptual basis of adaptive collaborative approaches and is therefore, perhaps unavoidably, dense. Things then get more interesting with chapters describing the lived experience of researchers and practitioners experimenting with these approaches in practice. Carol Colfer's contribution is a reassuringly frank and personal reflection on the issues underlying conflicts and collaborations between social and natural scientists within an international research institute. Helpfully she identifies four criteria for success, including identifying a problem of sufficient significance that participants are motivated to act, the importance of excellent facilitation skills, the 
need for an institutional environment that grants freedom to fail and to learn from those failures, and the crucial issue of sufficient time not just to understand context and build relationships but also for implementation, monitoring and review of planned activities.

Further chapters explore a wide range of case studies. These include: adapting the Farmers Field School approach initially developed with rice farmers in South Asia to the upland landscapes of Ecuador, community networks for floodplain management in Bangladesh, adaptive collaborative approaches in the contested forest landscapes of Zimbabwe, and forest governance in Nepal. Chapter 8 is a personal reflection of the use of action research in natural resource management by Robert Fisher, ex Deputy Director of the Regional Community Forestry Training Center in Bangkok. Fisher is an anthropologist and brings his experience as both an academic and a development practitioner to bear in highlighting challenges and lesson learnt. He also helpfully provides what he calls 'pragmatic' definitions of terms such as applied research, participatory action research and adaptive management, which are liberally used in the rest of the book but often with much less clarity.

The final two chapters, authored by the editors, attempt to summarize the challenges highlighted in the other contributions and to present what they refer to as a bold new future direction. Perhaps the best way for me to conclude is with one further quote, this time from the final chapter: 'Paradigmatic rethinking is needed to move beyond biophysical reductionism, a linear conception of change, a thin view of participation, technical views of innovation and learning framed within existing assumptions and underlying institutional boundaries and regimes.' With that, I'll leave it to you to decide if this is the kind of book for you.

HELEN SCHNEIDER Fauna \& Flora International, Cambridge, UK

E-mail helen.schneider@fauna-flora.org

\section{Historical Environmental Variation in Conservation and Natural Resource Management edited by John A. Wiens, Gregory D. Hayward, Hugh D. Safford and Catherine Giffen (2012), xiv + 337 pp., Wiley-Blackwell, Oxford, UK. ISBN 9781444337938 (pbk), GBP 40.00.}

'What's past is prologue' is a phrase well known to most of us. Like so many pithy phrases it comes originally from William Shakespeare, this time in his play The Tempest. But many of us (including me, until I looked it up) let slip from our memory what comes next: "What to come, in yours and my discharge.'
This book includes both elements. It reminds us how important the historical perspective is for natural resource managers but also makes the even stronger point that what happens next is in the hands of today's resource managers. After all, the world has never before had over seven billion people, subjecting many natural resources to unprecedented pressures in the form of anthropogenic climate change, habitat modification, pollution and novel technologies that may have unexpected consequences. Against this background the book starts with a review of the theoretical and conceptual background of the historical range of variation (defined as 'the variation of ecological characteristics and processes over scales of time and space that are appropriate for a given management application'), which sets appropriate limits on 'history' to include only that on which research can provide good information. It then develops concepts of historical ecology and how they can be applied to resource management and conservation. It clearly identifies the key issues and challenges for those who would like to build an historical dimension into their thinking about modern resource management. Forget about climax vegetation. Critically consider how 'new' ecosystems draw from historical elements. Find a place for humans in the natural world (perhaps using 'social range of variation', a term also introduced here). Remember Darwin's edict that the fittest are those best able to adapt to changing conditions, not necessarily the smartest or strongest. Recognize that while historical evidence on forests (such as pack-rat middens in the American West, old fire-scarred trees, ancient dead wood and so forth) can be informative, little historical evidence is available on the understorey, soil microbial communities, and invertebrate communities.

Two chapters focus on modelling historical variation and its application for understanding future variation, followed by a series of case studies from various parts of North America (e.g. the Colorado Front Range, coastal temperate rainforests of British Columbia, Minnesota's national forests) and several on ecosystem types (river floodplains, streams). I was especially interested in the five chapters that provided perspectives from other parts of the globe, including Africa, Australia, and the Fennoscandian taiga. These helped to broaden the perspective of the book and suggest how it can be applied to virtually any part of the world where time series data can be supportive. The book concludes with reflections of history in a non-stationary world and the growing importance of the past in managing ecosystems of the future.

It may be useful to recall that it is seldom ecosystems that are managed but rather people and the demands they place on ecosystems and the services their functions provide. These demands are growing, thereby increasing the challenges for resource managers in a time when 'regulation' often seems like a dirty word, especially to those whose actions affecting natural resources most need to be regulated. The book's call for using the historical record to assess how forests (the book is mostly about forest management) responded to environmental variations in the past as a way to inform current and future management is therefore timely.

The chapter by A.R.E. Sinclair, drawing on 50 years of ecological research in the greater Serengeti ecosystem of Tanzania, was especially useful in challenging the implicit premise, even promise, of protected areas: that once a legal boundary has been established and the site is well managed it should remain ecologically stationary forever and management should act to keep it thus.' He suggests that history poses two major challenges to the current conservation paradigm. Firstly, all ecosystems change, sometimes quite suddenly and even to a quite different state. Secondly, those who value current ecosystems must provide ways for them to move to new locations. One implication of these challenges is that in many parts of the world, further conflict between people and the rest of nature is inevitable.

This book also brings a bonus with it: a companion website (www.wiley.com/go/ wiens/historicalenvironmentalvariation) that contains figures and tables from the book, and much else besides. This may well become the norm for many such data-rich books, as publishers seek to reduce the cost of hard copies and make more information available to a wider audience.

Incorporating historical environmental variation into modern thinking about conservation and the management of living natural resources deserves greater attention from the readers of this journal. This book provides an excellent overview of the lessons that can be drawn. For example, human use of certain ecosystem services has closed off other services, so one type of success can discourage other potentials. As Haila suggests in his chapter on the Fennoscandian taiga, 'It is worth trying tools of thinking such as ecohistorical periods and phase space representations of environmental change. Our main challenge is to assess the viability of alternative types of success and draw conclusions.'

The book concludes with 10 history-based recommendations to resource managers, of which I will cite only the last: 'Plan for the future, not for the past, but do not forget that the past provides our only empirical glimpse into the likely course of the future.'

JEFF MCNEELY IUCN, Gland, Switzerland E-mail jeff.moneely@iucn.org 